\title{
Método para cálculo de emolumentos de serviços públicos: uma aplicação ao transporte rodoviário internacional de cargas
}

\author{
Hugo Alves Silva Ribeiro \\ Agência Nacional de Transportes Terrestres (ANTT)
}

Gizelle Coelho Netto

Agência Nacional de Transportes Terrestres (ANTT)

Nathane Eva Santos Peixoto

Instituto Federal de Brasília (IFB)

Carlos Henrique Rocha

Universidade de Brasília (UnB)

Para realizar determinados serviços, algumas entidades públicas brasileiras realizam cobranças de valores. Esses montantes podem ser tratados como taxas, contribuições ou emolumentos. Em se tratando especificamente de emolumentos, o valor a ser cobrado deveria considerar o custo de utilização efetiva ou potencial do serviço público realizado, não podendo contemplar fatos geradores idênticos àqueles abarcados por impostos. Diante da dificuldade que algumas instituições têm para determinar os valores de cobrança dos emolumentos, este artigo tem por objetivo propor um método de cálculo capaz de facilitar e fundamentar a tomada de decisão dos gestores. O método desenvolvido adaptou conceitos inerentes ao Standard Cost Model, amostragem do trabalho e custeio baseado em atividades ( $A B C)$. Para analisar a viabilidade de implantação, essa técnica foi aplicada a uma das atividades da Agência Nacional de Transportes Terrestres que realiza a cobrança de emolumentos. Como resultado, o método se apresentou satisfatório para a finalidade proposta.

Palavras-chave: emolumentos, método de cálculo, MIVE

[Artigo recebido em 19 de dezembro de 2017. Aprovado em 29 de abril de 2019.] 
Método para el cálculo de emolumentos de servicios públicos: una aplicación al transporte internacional de mercancías por carretera

Para realizar determinados servicios algunas entidades públicas brasileñas realizan cobros de valores. Estos importes pueden ser tratados como tasas, contribuciones o emolumentos. En lo que se refiere específicamente a emolumentos, el valor a ser cobrado debería considerar el costo de utilización efectiva o potencial del servicio público realizado, no pudiendo contemplar actividades idénticas a aquellas abarcadas por impuestos. Ante esta dificultad que algunas instituciones tienen para determinar los valores de cobro de los emolumentos, este artículo tiene por objetivo proponer un método de cálculo capaz de facilitar y fundamentar la toma de decisión de los gestores. El método desarrollado adaptó conceptos inherentes al Standard Cost Model, muestreo del trabajo y costeo basado en actividades ( $A B C$ ). Para analizar la viabilidad de implantación, esa técnica fue aplicada a una de las actividades de la Agencia Nacional de Transportes Terrestres que realiza el cobro de emolumentos. Como resultado, el método se presentó satisfactorio para la finalidad propuesta.

Palabras clave: emolumentos, método de cálculo, MIVE

\section{Method for emolument calculating: an application to international road freight transport}

To perform certain services some Brazilian public entities charge values. These amounts can be treated as fees, contributions or emoluments. When dealing specifically with emoluments, the amount to be charged should consider the cost of effective or potential use of the public service performed, and cannot contemplate identical activities to those covered by taxes. In view of the difficulty that some institutions have in determining the emoluments values, this paper aims to propose a calculation method capable of support the decision-makers. The developed method adapted concepts inherent to the Standard Cost Model, work sampling and Activity Based Costing ( $A B C)$. In order to analyze the feasibility of implantation, this technique was applied to one of the activities of the National Land Transport Agency that charges emoluments. As a result, the method was satisfactory for the proposed.

Keywords: emoluments, method of calculation, MIVE 


\section{Introdução}

A cobrança de emolumentos é muito comum no serviço público brasileiro. Seu fundamento jurídico foi dado pelo artigo 98 da Constituição Federal, ao estabelecer que os "emolumentos serão destinados exclusivamente ao custeio dos serviços afetos às atividades específicas" (BRASIL, 1988). O emolumento é considerado um serviço público prestado em caráter particular (SABBAG, 2010), e tratado como taxa pelo Supremo Tribunal Federal (BRASIL, 1995; 1999), fazendo com que as diretrizes do art. 77 da Lei no 5.172/1966 devam ser seguidas:

Art. 77. As taxas cobradas pela União, pelos Estados, pelo Distrito Federal ou pelos Municípios, no âmbito de suas respectivas atribuições, têm como fato gerador o exercício regular do poder de polícia, ou a utilização, efetiva ou potencial, de serviço público específico e divisível, prestado ao contribuinte ou posto à sua disposição.

Parágrafo único. A taxa não pode ter base de cálculo ou fato gerador idênticos aos que correspondam a imposto nem ser calculada em função do capital das empresas (BRASIL, 1966).

Diante disso, interpreta-se que o cálculo de emolumentos deve considerar a utilização "efetiva" ou "potencial" de serviço público específico e divisível, não podendo contemplar fatos geradores idênticos àqueles abarcados por impostos. Como consequência, determinar o valor a ser cobrado pelo serviço público torna-se uma atividade complexa, justificando estudos mais aprofundados.

Este artigo tem por objetivo desenvolver um método de cálculo de emolumentos que atenda à legislação brasileira, capaz de ser adaptado a qualquer instituição pública interessada, a fim de fundamentar a tomada de decisão da entidade gestora. Para validação dessa técnica, decidiu-se por aplicá-la aos serviços de habilitação do transporte rodoviário internacional de cargas, sob competência da Agência Nacional de Transportes Terrestres (ANTT), devido à sua maior complexidade, tendo em vista a necessidade de satisfazer o princípio da reciprocidade com os demais países, e se adaptar à realidade dos transportadores, os quais são o elo principal da logística internacional. O método desenvolvido adaptou conceitos do Standard Cost Model, amostragem do trabalho e custeio baseado em atividades.

\section{Referencial teórico}

Considerando que a cobrança de emolumentos deve seguir aquilo estabelecido pela supracitada Lei no 5.172/1966 (BRASIL, 1966, 1995, 1999), o principal desafio está em identificar os valores dos recursos utilizados "efetivamente" e "potencialmente" 
para realização de determinada tarefa. Sabendo que o custo pode ser definido como o gasto relativo aos bens e serviços utilizados na realização da atividade (MARTINS, 2003), pode-se entender por custos "efetivos" aqueles incorridos na execução do serviço (STEPHEN, 1993), enquanto os custos "potenciais" são tratados pelos economistas como custos de oportunidade (VARIAN, 2003), cujo cálculo é um desafio e se torna uma preocupação constante para o gestor (CATELLI et al., 2014).

Existe uma técnica desenvolvida com a finalidade de identificar os diversos "custos administrativos" das instituições, oriundos da necessidade de cumprimento de suas obrigações legais. Essa ferramenta é chamada de standard cost model (SCM) ou modelo de custo padrão, e consiste em uma das etapas para determinar os gastos que uma empresa tem para cumprir com as imposições regulatórias do governo (Organisation fOR ECONOMIC COOPERATION AND DEVELOPMENT, 2004).

Por exemplo, uma empresa que adquire filtros para cumprir com as cotas de emissão de poluentes possui um "custo de conformidade substantivo", o qual é um gasto para se adequar ao regulamento estatal (ORGANISATION FOR ECONOMIC Co-OPERATION AND DEVELOPMENT, 2004). Do mesmo modo, a empresa deve arcar com os impostos, tributos, emolumentos e eventuais multas, também exigidos pelo governo, que são tratados como custos financeiros (ORGANISATION FOR ECONOMIC CO-OPERATION AND DEVELOPMENT, 2004). Ademais, existem outros custos normalmente não contabilizados, que são oriundos da produção e submissão dos documentos necessários para a instalação dos filtros ou a manutenção de registos da emissão de agentes poluentes, que são chamados de custos administrativos (Organisation for ECONOMIC Co-Operation AND DeVElopMent, 2004). O SCM foi desenvolvido para determinar esses custos administrativos das empresas (Figura 1), também entendidos como custos burocráticos.

\section{Figura 1 - Âmbito de aplicação originalmente proposto pelo SCM}

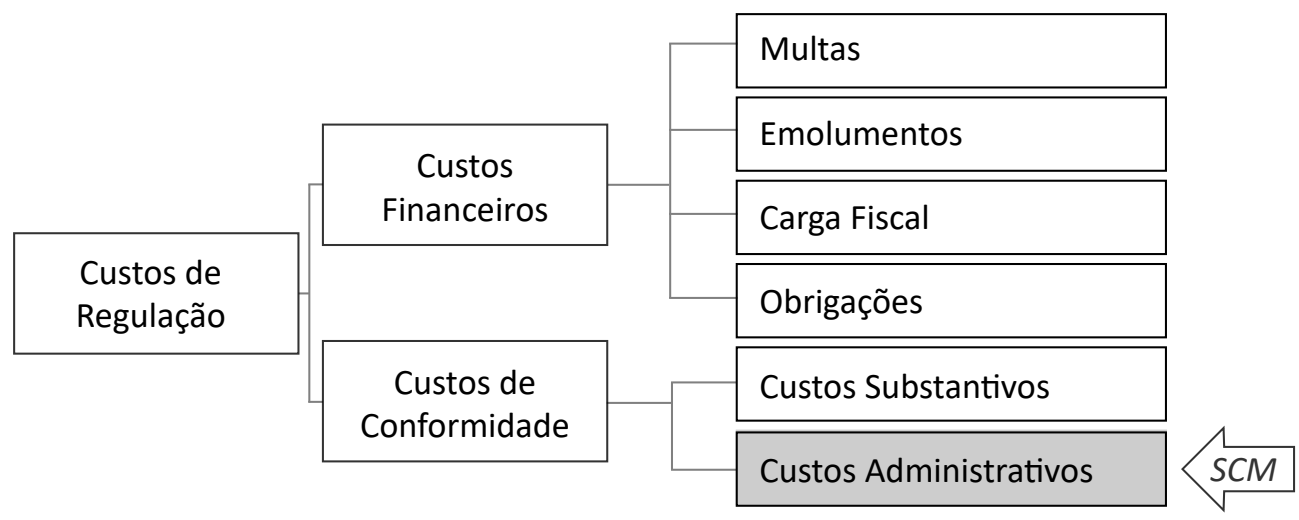

Fonte: adaptado da OECD (2004). 
O modelo de custo padrão foi desenvolvido no início do século 21 na Holanda (NIJSEN; VELLINGA, 2002) e já está sendo utilizado, em nível global, em diversos setores de interesse público, tais como: determinação de custos no setor de transporte público urbano da Itália (AVENALI et al., 2016); redução no custo de tratamento de câncer em hospital universitário da Bélgica (NEYT et al., 2005); ou redução dos custos de transições econômicas gerados pela implementação regulatória das autoridades governamentais, conforme estudos da Universidade de Amsterdam (DEN-BUTTER; De-GraAF; NiJSEN, 2009).

A preocupação com os custos aplicados ao setor público envolve autoridades do mundo e vem sendo tratada há vários anos (VAZAKIDIS; KARAGIANNIS; TSIALTA, 2010; OSEIFUAH, 2014). No Brasil, o trabalho de Silva, Davis e Viveiros (2014) consolidou um extenso referencial teórico sobre a contabilidade de custos direcionados à administração pública, no sentido de estabelecer os Gastos de Posse Estratégica na Marinha do Brasil, ao passo que Borinelli et al. (2014) relata a importância de identificar os custos vinculados à prestação de serviços públicos para a cobrança de emolumentos.

Luque et al. (2008) apresentam alguns modelos conceituais para a identificação dos custos, enquanto Alonso (1999) propõe que seja utilizada a técnica de "custeio baseada em atividades" (Activity-Based Costing - ABC). Nesse método, os custos são inicialmente atribuídos às atividades e, posteriormente, aos produtos e serviços. A técnica apoia-se no conceito de que cada tarefa consome recursos e, consequentemente, dinheiro (MAHER, 2001). Por meio dele é possível proporcionar uma boa referência de custos, inclusive facilitar a identificação de custos de oportunidade das atividades do serviço público.

O trabalho de Hamann et al. (2014) aplicou o custeio ABC como mecanismo de custos para o Poder Judiciário do Distrito Federal. Já Amaral et al. (2014) citaram que o Sistema de Informações de Custo (SIC) do Governo Federal, embora importante para fixar preços públicos e taxas, não seria capaz de obter os custos diretos dos serviços ofertados, os quais exigiriam maiores detalhamentos e mensurações. É nesse sentido que esta pesquisa pretende avançar, aliando métodos já existentes para facilitar a definição de valores de emolumentos comumente cobrados no serviço público brasileiro.

No entanto, mesmo propondo a utilização conjunta das técnicas do SCM e do custeio $A B C$, ainda permanece um entrave: identificar o tempo da realização de atividades do serviço público para fins de rateio dos custos levantados. Por essa razão que este artigo propõe a adaptação do método conhecido por amostragem do trabalho, uma complementariedade das técnicas desenvolvidas por Frederick Taylor intitulada por cronoanálise, que buscava determinar o tempo necessário 
para conclusão dos processos de uma instituição (CHIAVENATO, 2006). O método de amostragem do trabalho foi originalmente desenvolvido na indústria têxtil inglesa (BARNES, 1977) com o propósito de possibilitar a coleta de informações acerca da distribuição das atividades da fábrica em um dia de trabalho (NORDSTROM, 1961).

De forma simplificada, a técnica de amostragem do trabalho consiste em fazer observações diretas em intervalos de tempo aleatórios ou sistemáticos, de um ou mais operadores, e analisar o seu trabalho produtivo. Durante a observação, verificase apenas se uma tarefa está sendo ou não realizada, assim, não é feita medida de tempo efetivamente. $O$ tempo de realização da atividade é estimado utilizando-se a proporção do tempo entre o número de observações realizadas durante um período de trabalho e quantidade de itens produzidos (LIBRELOTTo et al., 2000).

\section{Método de pesquisa}

Diante do exposto, este artigo desenvolveu o método de identificação de valores de emolumentos (MIVE), o qual mescla elementos de três técnicas distintas: SCM, custeio $A B C$ e amostragem do trabalho (Figura 2). Essa técnica foi elaborada para fundamentar a tomada de decisão do gestor público a respeito do cálculo de emolumentos que atenda à legislação brasileira.

Figura 2 - Enquadramento metodológica do método de identificação dos valores de emolumentos (MIVE)

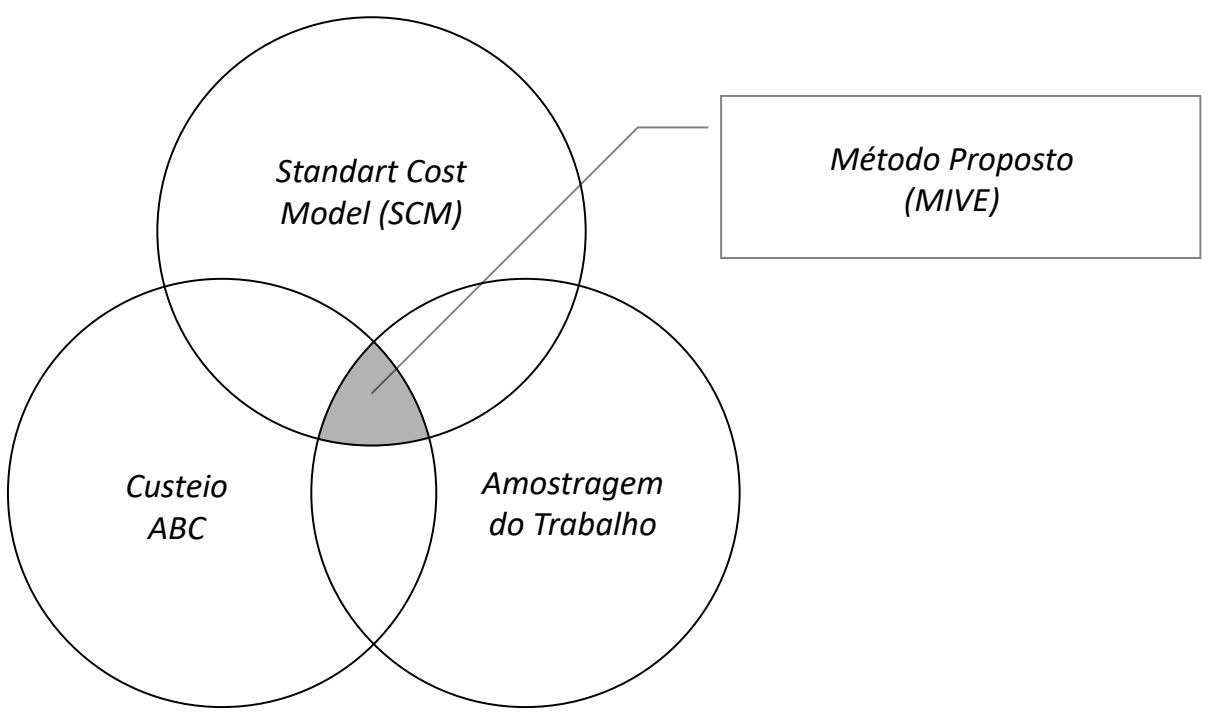

Fonte: elaboração própria. 
As etapas metodológicas do MIVE foram adaptadas do SCM, enquanto as técnicas de identificação dos custos foram oriundas do método do custeio $A B C$, cujo rateio foi dado por meio dos tempos obtidos mediante as adequações da amostragem do trabalho. Com essa abordagem, o MIVE consiste nos seguintes passos:

- Etapa 1: mapeamento das atividades (dos processos).

- Etapa 2: identificação do tempo despendido por atividade.

- Etapa 3: identificação dos custos efetivos incorridos na execução do serviço.

- Etapa 4: identificação dos custos potenciais que envolvem a atividade por meio do rateio dos eventuais custos de oportunidade.

- Etapa 5: identificação do custo total da atividade (valor do emolumento).

- Etapa 6: análise comparativa do custo total identificado.

A primeira etapa se refere ao mapeamento das atividades (dos processos), que permite representar, de forma lógica e sequencial, o serviço efetivamente realizado. O trabalho de Pinho et al. (2007) apresenta várias técnicas para esse mapeamento, mas dá enfoque em duas delas: fluxograma e mapa de processos (RIBEIRO, 2015). A utilização de cada técnica dependerá do interesse do gestor, e a elaboração desse mapa é pré-requisito para continuidade do MIVE.

A segunda etapa do método consiste no cálculo do tempo despendido por cada atividade. A identificação desse tempo é essencial tendo em vista que o rateio dos custos terá como referência essa variável. Caso a atividade realizada seja baseada em processos bem definidos e altamente repetitivos, recomendase a utilização da técnica de cronoanálise, ou seja, a cronometragem do tempo de operação (BARNES, 1982). No entanto, como boa parte do serviço público possui processos com atividades mistas realizadas por um mesmo operador, bem como deve contemplar tempos de filas processuais, a adaptação da técnica de amostragem do trabalho pode-se apresentar mais atrativa (NORDSTROM, 1961). Como resultado, essa técnica possibilita ter um panorama geral do percentual do tempo que cada atividade está consumindo.

A terceira etapa exige a identificação de todos os gastos efetivamente existentes para realização da atividade. Entre eles, podem-se citar o custo direto de pessoal, o custo indireto de pessoal (custos gerenciais, por exemplo) e o custo com instalação física do departamento.

A quarta etapa amplia o rol dos gastos ao inserir os custos potenciais e custos de oportunidade, tais como o custo com eventuais cobranças judiciais ou multas. Destaca-se que quando não é possível identificar custos potenciais, podem-se realizar aproximações percentuais, como, por exemplo, aquelas utilizadas pelos aplicadores do SCM, que sugerem adicionar de $20 \%$ a $30 \%$ do valor obtido para os 
gastos efetivos, o qual é conhecido por "overhead" (ORGANISATION FOR ECONOMIC Co-Operation AND DEVElopment, 2004).

A quinta etapa do MIVE trata do simples somatório dos custos identificados nas etapas anteriores a fim de determinar o custo total de cada atividade. Por fim, a sexta etapa propõe que o resultado obtido seja analisado no ambiente em que o emolumento é cobrado, verificando a conveniência de exigir que a sociedade pague o montante calculado para a realização do serviço. Caso o valor encontrado seja muito superior àquele que a população estaria disposta a pagar, há indicativos de que o fluxo deve ser revisto, na tentativa de identificar eventuais desperdícios no processo. A Figura 3 resume o método proposto.

Figura 3 - Método de identificação de valores de emolumentos (MIVE)

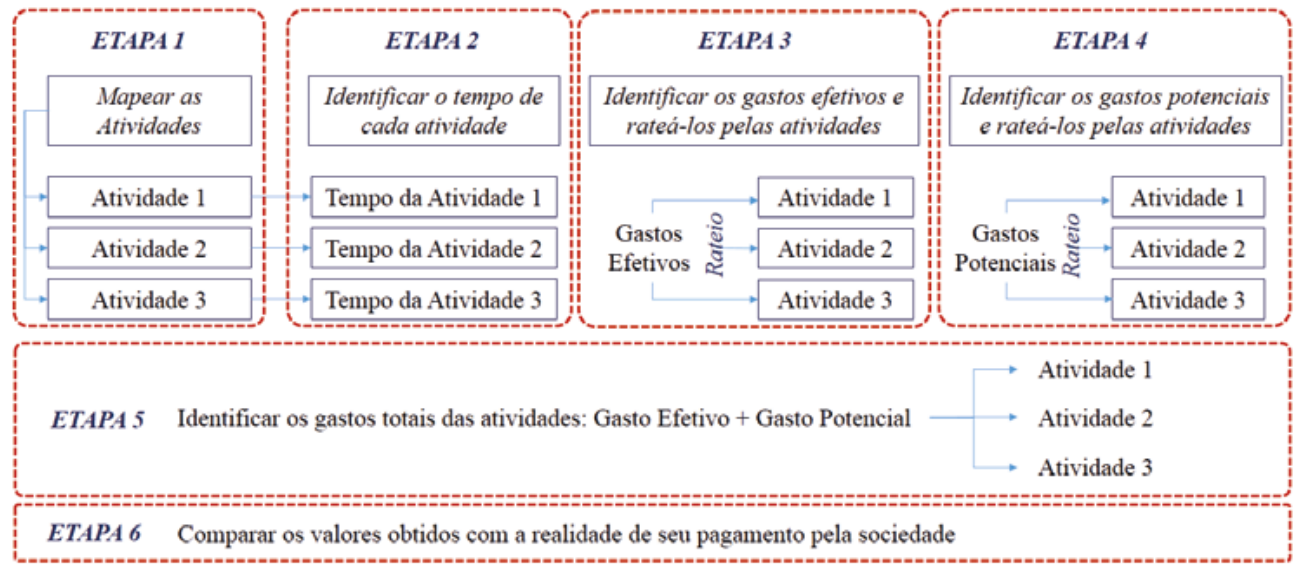

Fonte: elaboração própria.

\section{Aplicação do método para cálculo de emolumentos}

Para verificar a viabilidade de utilização do MIVE, essa técnica foi aplicada em uma das atividades da Agência Nacional de Transportes Terrestres (ANTT), que realiza a cobrança de emolumentos. Entre as diversas atribuições, essa autarquia tem por finalidade regular, supervisionar e fiscalizar as atividades relacionadas à prestação de serviços e à exploração de infraestrutura de transportes terrestres (BRASIL, 2001). Considerando os serviços que possuem cobrança de emolumentos, destaca-se a habilitação do transportador rodoviário internacional de cargas, a qual é de grande complexidade e pode envolver aspectos relacionados às negociações internacionais.

Em se tratando do transporte rodoviário internacional de cargas (TRIC), existem duas classes de habilitação: uma para o transportador brasileiro e outra para o 
transportador estrangeiro. No primeiro caso, de forma simplificada, o transportador brasileiro que pretende transportar regularmente mercadorias para um segundo país deve:

1. Solicitar, à ANTT, uma "licença originária" (LO) do Brasil para o país de destino.

2. Solicitar, à autoridade do país de destino, uma licença complementar daquele país.

3. Apresentar a licença complementar daquele país à ANTT, informando que houve autorização para o transporte.

No que tange à classe da transportadora estrangeira, caso deseje transportar carga para o Brasil, ela deverá obter a licença originária em seu país e, posteriormente, requerer à ANTT a Licença Complementar (LC) brasileira. A Figura 4 representa, de forma exemplificativa, essas situações para o caso de uma transportadora brasileira que deseja transportar para a Argentina, bem como o caso recíproco de uma transportadora argentina que pretenda transportar para o Brasil.

Figura 4 - Representação esquemática que indica que a ANTT emite LO apenas para empresas brasileiras e LC apenas para empresas estrangeiras

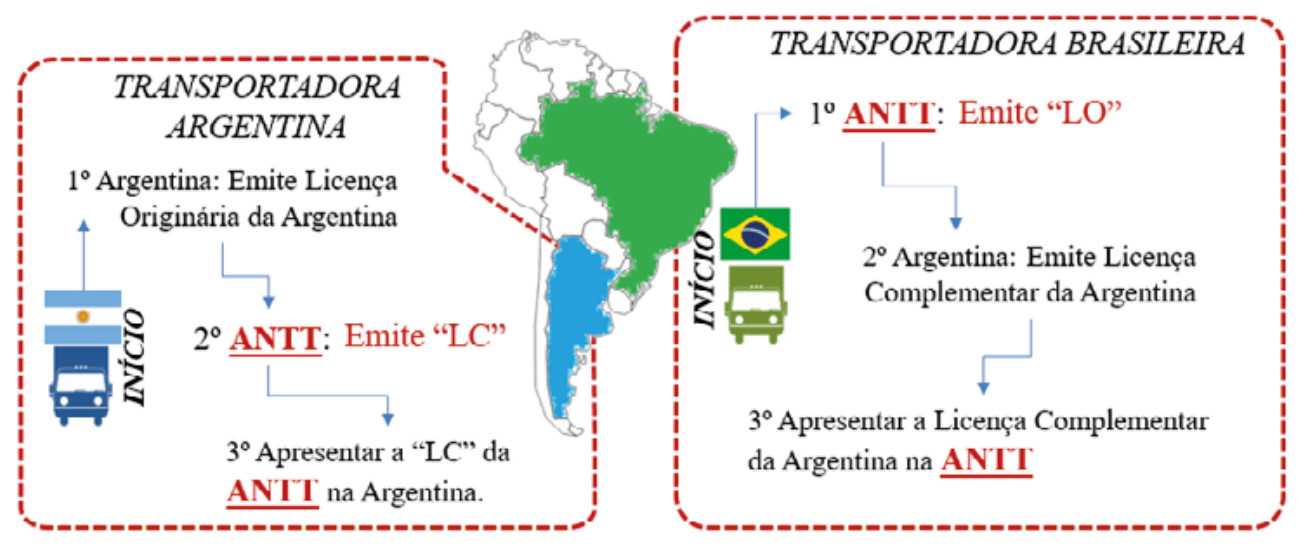

Fonte: elaboração própria.

Ainda em referência à classe do transportador brasileiro não habilitado, na hipótese de precisar transportar, ocasionalmente, uma carga sem regularidade, ele deverá solicitar à ANTT a autorização de viagem ocasional (VO). Agora, supondo que o transportador brasileiro já seja habilitado para o TRIC com algum país, caso ele venha a precisar apenas alterar a sua frota cadastrada, deverá solicitar à ANTT a modificação de frota (MF).

Tanto a transportadora brasileira quanto a estrangeira que deseje receber uma declaração física da ANTT informando a sua frota cadastrada no Brasil deve solicitar 
à agência o relatório de frota (conhecido por Modelo A). Segundo a Resolução ANTT no 1.474/2006 (AgÊnCIA NACIONAL DE TRANSPORTES TERRESTRES, 2006), que estabelece os procedimentos para o TRIC, os valores vigentes em 2017 dos emolumentos para cada um desses processos são aqueles descritos no Quadro 1:

Quadro 1 - Valores de emolumentos cobrados pela ANTT para os serviços de TRIC em 2017

\begin{tabular}{ll}
\hline Documento & Valor \\
\hline Licença originária (LO) & $\begin{array}{l}\mathrm{R} \$ 180,00 \text { por solicitação, com adicional de } \mathrm{R} \$ 5,00 \\
\text { por unidade (veículo cadastrado) }\end{array}$ \\
\hline $\begin{array}{l}\text { Autorização de viagem } \\
\text { ocasional (VO) }\end{array}$ & $\begin{array}{l}\mathrm{R} \$ 10,00 \text { por solicitação, com adicional de } \mathrm{R} \$ 5,00 \text { por } \\
\text { unidade (veículo cadastrado) }\end{array}$ \\
\hline Modificação de frota (MF) & $\begin{array}{l}\mathrm{R} \$ 10,00 \text { por solicitação, com adicional de } \mathrm{R} \$ 5,00 \text { por } \\
\text { unidade (veículo cadastrado) }\end{array}$ \\
\hline 2a via de LO & $\mathrm{R} \$ 180,00$ \\
\hline Licença complementar (LC) & $\mathrm{R} \$ 180,00$ \\
\hline 2a via de LC & $\mathrm{R} \$ 180,00$ \\
\hline $\begin{array}{l}\text { Relatório de frota existente } \\
\text { (Modelo A) }\end{array}$ & $\mathrm{R} \$ 50,00$ \\
Fonte: adaptado de ANTT (2006). & \\
\hline
\end{tabular}

Pode-se perceber que há cobranças de valores fixos e, em alguns casos, valores variáveis de acordo com a quantidade de veículos cadastrados. Isso faz com que eventuais atualizações de valores se tornem bastante complexas. Como os emolumentos não sofrem alterações desde 2003 (AGÊNCIA NACIONAL DE TRANSPORTES TERRESTRES, 2003), é pertinente buscar meios para atualizá-los, tanto em seus montantes quanto em seus procedimentos, especialmente devido à necessidade de adequação às tecnologias atualmente disponíveis. Diante disso, a revisão das atividades e dos valores de cobrança referentes ao TRIC fez com que esse processo fosse candidato à aplicação do MIVE.

\section{Etapa 1: mapeamento das atividades}

A fim de cumprir com essa primeira etapa do MIVE, todos os processos de emissão da LO, VO, MF, LC, Modelo A e 2a via de LO e LC foram mapeados por meio da técnica de mapa de processos. Como resultado desse mapeamento, concluiu-se que cada documento a ser emitido possui um fluxo característico, uma exigência documental e um esforço de análise distinto. Isso faz com que eventuais aguardos 
de determinados documentos, ou soluções de pendências, gerem filas durante o seu processamento. De forma geral, todos os processos passam pela etapa de recepção de documentos, processamento inicial, processamento final e emissão.

Enquanto era realizado o mapeamento do processo, identificou-se uma atividade adicional que não estava prevista anteriormente no regulamento da ANTT, chamada de renovação de licença complementar, que acabou sendo inserida na nova proposta de emolumentos. Também foi identificado que toda solicitação realizada à ANTT deve ser precedida de um requerimento, o qual exige documentos e comprovações do transportador. Por exemplo, para que uma transportadora solicite uma LO, ela deve apresentar, por meio de procurador, contrato social da instituição, Cadastro Nacional de Pessoal Jurídica (CNPJ), relação da frota a ser habilitada por destino e número do Registro Nacional do Transportador Rodoviário de Cargas (RNTRC). Consequentemente, uma análise de solicitação de LO realizada pela ANTT faz com que seja necessário verificar cada um desses documentos.

Ainda nessa etapa do MIVE, percebeu-se uma certa ineficiência nesse processo: redundância de envio documental. Por exemplo, uma transportadora $X$ que tenha interesse em transportar apenas para a Argentina deve apresentar à ANTT o rol de documentos da empresa, acrescido da relação de frota a ser habilitada. Em outro momento, caso a mesma transportadora $\mathrm{X}$ queira transportar para o Paraguai, ela deve apresentar novamente o mesmo rol de documentos, acrescidos da relação de frota a ser habilitada para esse novo país (Figura 5), o que geraria custos adicionais de envio pelo transportador e, também, de análise pela ANTT.

Figura 5 - Documentos necessário para uma transportadora brasileira $\mathrm{X}$ requerer uma LO para transportar para a Argentina e, posteriormente, para o Paraguai
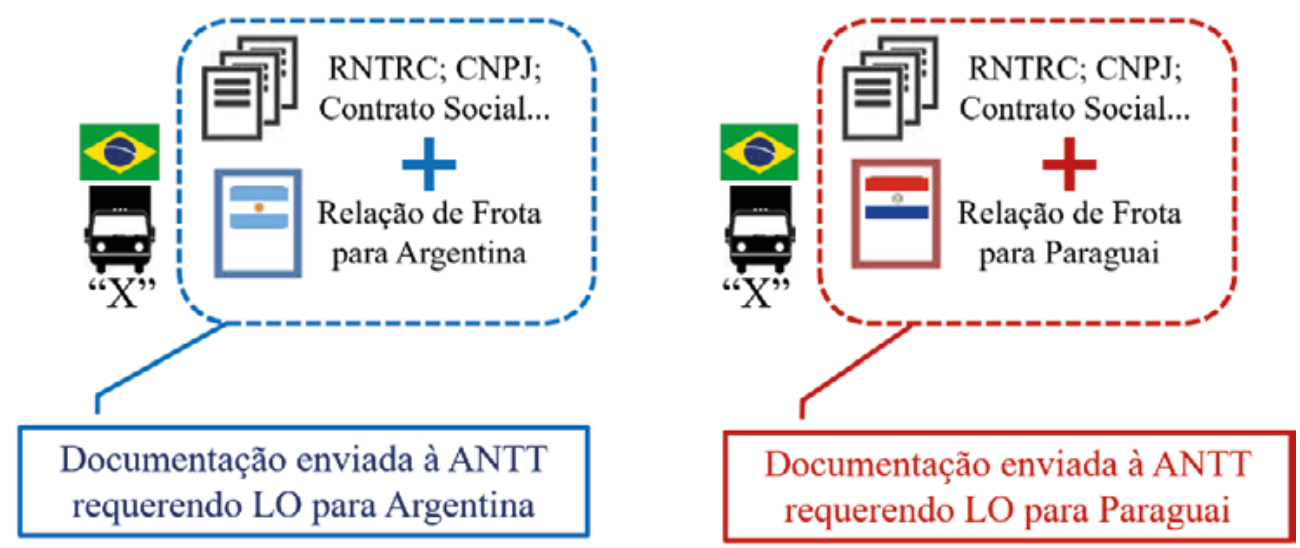

Fonte: elaboração própria. 
Para solucionar esse problema, adotou-se a seguinte diretriz durante o MIVE: adicionar um processo de Habilitação TRIC previamente à emissão da LO, contemplando os documentos principais (RNTRC, CNPJ, Contrato Social etc.) e fazendo com que a LO seja uma simples autorização da frota habilitada (Figura 6). A partir dessa diretriz, pretende-se consolidar o pagamento de emolumentos apenas no processo de Habilitação TRIC, o qual realmente exige análise documental, sendo que as emissões das LOs acabam por se tornar apenas atividades simplificadas que não justificariam cobranças à sociedade.

Figura 6 - Proposta de simplificação administrativa para uma transportadora brasileira $X$ requerer uma Habilitação TRIC e, posteriormente, solicitar as LOs para a Argentina e Paraguai

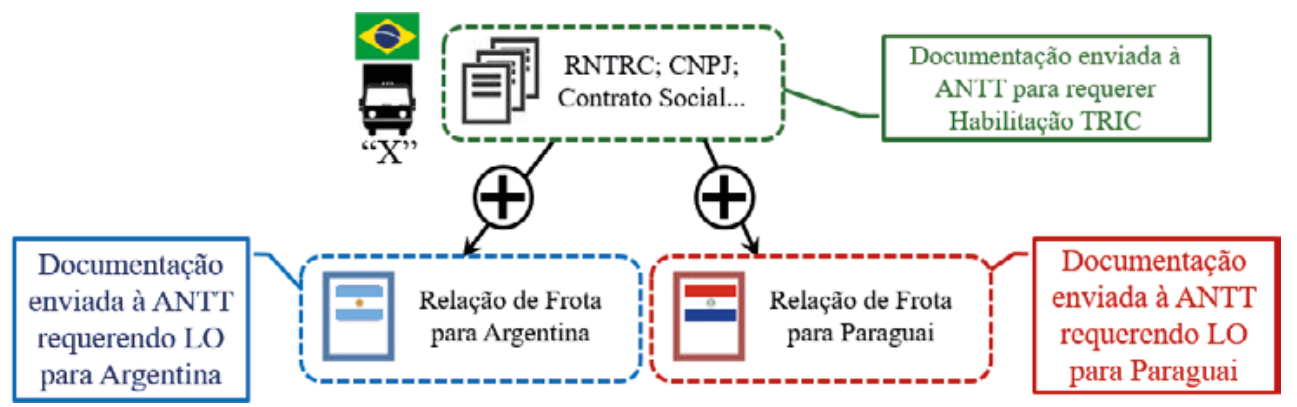

Fonte: elaboração própria.

Outra incongruência identificada durante o mapeamento do processo foi que diversas solicitações de VO na verdade não eram puramente "ocasionais". Isso porque, sempre que uma empresa transportava carga própria, ela acabava solicitando uma VO. A movimentação de carga própria deveria ser tratada de forma diferenciada, pois ela não se configura como um transporte remunerado, não admitindo emissões de LO para essa finalidade. Portanto, a proposta levantada durante essa primeira etapa do MIVE é de manter a VO para viagens efetivamente ocasionais e criar outra autorização para o transporte de carga própria, intitulada de autorização de TRIC própria.

Por último, foi possível identificar pelo mapa do fluxo que muitas empresas transportadoras cometiam equívocos no cálculo do valor do emolumento, especialmente na solicitação de LO, VO e MF, em que há cobrança adicional por cada veículo no requerimento. Nesse sentido, a aplicação do MIVE a esse caso concreto buscou utilizar um valor único por requerimento que independe da quantidade de veículos. Isso reduz a falha dos transportadores e, consequentemente, os esforços de correção dessas falhas pela ANTT. 
Portanto, nessa primeira etapa do MIVE foi possível analisar o panorama geral das atividades que exigem cobranças de emolumentos e direcionar os próximos passos na busca pela eficiência administrativa. A intenção foi propor melhorias no processo a fim de reduzir desperdícios e racionalizar o uso de recursos públicos.

\section{Etapa 2: identificação do tempo despendido por atividade}

Para identificar o tempo despendido na realização das atividades, buscou-se adequar, à realidade da ANTT, a técnica conhecida por amostragem do trabalho. Como apresentado anteriormente, cada processo possui um fluxo distinto, fazendo com que fosse necessário adequar essa técnica para identificar melhor o tempo despendido para a realização de cada atividade. Em resumo, o problema verificado foi que a amostragem não seria verdadeiramente efetiva devido às diversas atividades que um mesmo colaborador promovia. Isso faria com que, se fosse realizada amostragem aleatória, o processamento de alguma solicitação menos frequente, tal como a renovação de licença complementar, poderia não ser visualizado.

Devido a isso, o método originalmente instituído sofreu algumas adaptações. A principal delas é que, em vez da amostragem de observações, decidiu-se utilizar o censo (universo) de todos os requerimentos processados dentro de determinado período. Para tanto, em substituição à observação aleatória do colaborador, decidiu-se fazer com que o próprio colaborador anotasse, em um formulário que acompanhou todo o processo, o instante de início e término de cada atividade, bem como qual atividade foi realizada. O resultado desse formulário preenchido foi a anotação do período exato de realização de cada operação. O modelo do formulário utilizado está resumidamente apresentado na Figura 7.

\section{Figura 7 - Modelo de formulário utilizado}

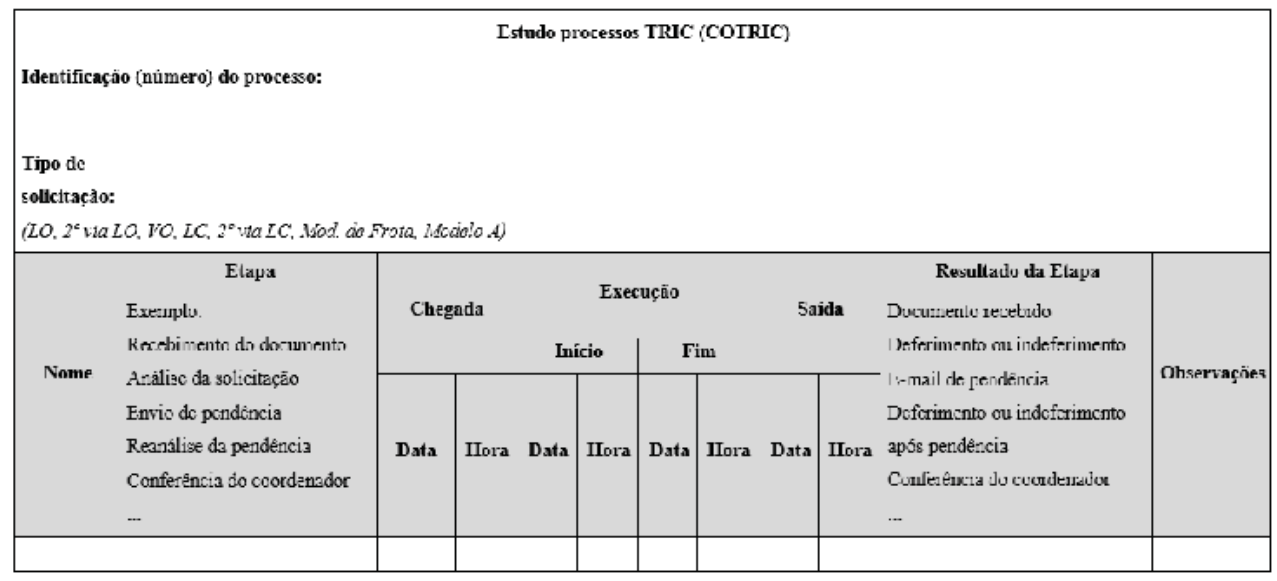

Fonte: elaboração própria. 
O formulário foi desenvolvido especialmente para permitir o monitoramento de cada tipo de solicitação: licenças originárias (LO), licenças complementares (LC), modificações de frota (MF), emissão de relatório de frota (Modelo A), viagens ocasionais (VO), e segunda via de documentos (licença originária e licença complementar). Destaca-se que, para cada requerimento, um formulário é preenchido com o histórico das atividades realizadas até a conclusão da solicitação.

O período escolhido para a coleta de dados foi o mês de junho de 2017 , devido à homogeneidade da quantidade de solicitações processadas. Essa escolha teve como base a quantidade e variedade de documentos analisados em 2016, conforme relatório gerencial da ANTT. No início do mês foi realizada a validação do modelo de formulário, e a coleta de dados se deu entre os dias 19 e 30 de junho de 2017. Durante esses 10 dias úteis de coleta de dados, foram preenchidos 111 formulários, cujos dados estão sintetizados Tabela 1.

Tabela 1 - Tempo médio obtido por tipo de atividade

\begin{tabular}{ccccccc}
\hline & A & B & C & D & E & F \\
\cline { 2 - 7 } Atividade & $\begin{array}{c}\text { Quantidade } \\
\text { de formulários }\end{array}$ & $\begin{array}{c}\text { Tempo } \\
\text { médio de } \\
\text { execução } \\
\text { por form. }\end{array}$ & $\begin{array}{c}\text { Tempo } \\
\text { médio de } \\
\text { espera por } \\
\text { form. }\end{array}$ & $\begin{array}{c}\text { Soma dos } \\
\text { tempos } \\
(B+C)\end{array}$ & $\begin{array}{c}\text { Tempo } \\
\text { total } \\
\text { (A X D) }\end{array}$ & $\begin{array}{c}\text { Tempo } \\
\text { total }\end{array}$ \\
\hline LC & 5 & $3: 24: 36$ & $171: 53: 36$ & $175: 18: 12$ & $876: 31: 00$ & $7,8 \%$ \\
\hline LO & 3 & $3: 02: 20$ & $138: 00: 47$ & $141: 03: 07$ & $423: 09: 20$ & $3,8 \%$ \\
\hline Mod. A & 7 & $0: 41: 34$ & $53: 05: 26$ & $53: 47: 00$ & $376: 29: 00$ & $3,3 \%$ \\
\hline MF & 84 & $1: 58: 57$ & $99: 27: 15$ & $101: 26: 12$ & $8520: 40: 29$ & $75,8 \%$ \\
\hline Ren. LC & 2 & $2: 32: 30$ & $151: 29: 00$ & $154: 01: 30$ & $308: 03: 00$ & $2,7 \%$ \\
\hline 2a via LC & 1 & $0: 28: 00$ & $47: 56: 00$ & $48: 24: 00$ & $48: 24: 00$ & $0,4 \%$ \\
\hline 2a via LO & 4 & $1: 14: 15$ & $67: 17: 00$ & $68: 31: 15$ & $274: 05: 00$ & $2,4 \%$ \\
\hline VO & 5 & $1: 06: 07$ & $82: 14: 27$ & $83: 20: 33$ & $416: 42: 47$ & $3,7 \%$ \\
\hline
\end{tabular}

Fonte: elaboração própria.

Para melhor entendimento dessa tabela, a coluna A representa a quantidade de formulários preenchidos que corresponde ao total de solicitações do período, enquanto a coluna $B$ apresenta o somatório do tempo médio despendido para executar a atividade correspondente (horas: minutos: segundos). A coluna $C$ corresponde ao tempo médio em que o requerimento ficou aguardando em fila. A coluna $D$ é o somatório dos tempos médios de execução e de espera, que corresponde ao tempo total despendido para cada solicitação, ou tempo de 
ciclo. A coluna E é o tempo total global que essa atividade demanda dentro do departamento responsável. A coluna F é o percentual dos tempos correspondentes à coluna $\mathrm{E}$.

Como conclusão, tem-se que o departamento responsável ocupa $75,8 \%$ de seu tempo processando solicitações de modificação de frota. Para fins de simplificação de rateio, foram agregadas todas as atividades referentes ao processamento e à emissão de LC e LO, especialmente devido à similaridade dessas operações. Portanto, o percentual de tempo total dos documentos relativos à LO, LC, renovação de LC e $2 \underline{a}$ via de LC e de LO foi de 17,2\% do tempo do departamento (Figura 8).

\section{Figura 8 - Percentual do tempo total despendido por cada atividade}

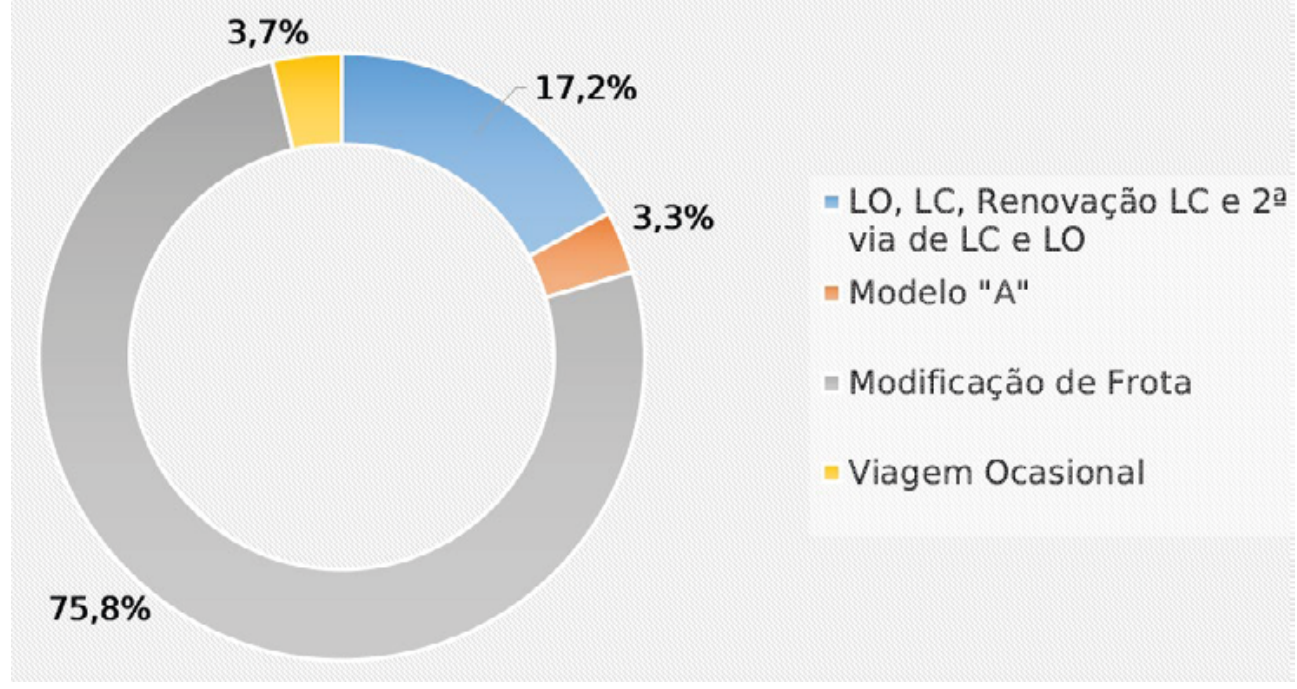

Fonte: elaboração própria.

\section{Etapa 3: identificação dos custos efetivos}

Essa terceira parte do MIVE centra esforços na identificação dos custos efetivos com cada atividade, considerando o estudo de tempos. Os custos tratados como efetivos são aqueles relativos aos gastos direto de pessoal, gerencial (ou indireto de pessoal) e instalação física da sede da ANTT. Devido à complexidade de rateio e obtenção de informações, não foram ponderados os custos de aquisição/ desenvolvimento de software utilizado nos processos do TRIC, de armazenamento e manutenção de banco de dados e arquivos eletrônicos, ou, até mesmo, suprimentos administrativos (tais como impressora, papéis e grampos).

O custo direto de pessoal foi obtido considerando os tempos calculados para cada operação por atividade realizada, a partir da coleta de dados e do salário 
do colaborador envolvido (ano-base 2016). Nessa análise, foram diferenciadas as atividades de auxiliar administrativo, técnico analista e superintendente, conforme o caso. Para calcular o custo direto de pessoal por solicitação foi multiplicado o custo (por hora) de cada operador envolvido na atividade pelo tempo médio de execução. Em resumo, foram obtidos os resultados da Tabela 2.

Tabela 2 - Custo direto de pessoal por atividade

\begin{tabular}{cc} 
Atividade & Custo direto de pessoal por solicitação \\
\hline LC & $\mathrm{R} \$ 144,00$ \\
\hline LO & $\mathrm{R} \$ 111,59$ \\
\hline Ren. LC & $\mathrm{R} \$ 113,53$ \\
\hline 2 ำ via LC & $\mathrm{R} \$ 17,77$ \\
\hline 2 o via LO & $\mathrm{R} \$ 55,46$ \\
\hline Modelo A & $\mathrm{R} \$ 30,48$ \\
\hline Mod. frota & $\mathrm{R} \$ 82,23$ \\
\hline VO & $\mathrm{R} \$ 46,43$ \\
\hline Fonte: elaboração própria. & \\
\hline
\end{tabular}

Para estimar o valor do custo direto de pessoal foi necessário realizar o cálculo separadamente para cada uma das seguintes atividades: LC, LO, Renovação de LC, $2^{\text {a }}$ via de LC e de LO, para, em seguida, agrupar o valor dessas atividades em um valor único, mantendo as atividades agrupadas conforme mostrou a Figura 8. A agregação foi dada pela ponderação da quantidade de formulários preenchidos. Como resultado, encontrou-se o custo médio direto de $\mathrm{R} \$ 101,43$ para cada uma das atividades agrupadas previamente (Tabela 3 ).

Tabela 3 - Custo médio ponderado de pessoal para a atividade agregada

\begin{tabular}{|c|c|c|c|}
\hline Documento & $\begin{array}{l}\text { Quantidade } \\
\text { de formulários } \\
\text { preenchidos }\end{array}$ & $\begin{array}{l}\text { Custo direto de } \\
\text { pessoal }\end{array}$ & Custo médio \\
\hline LC & 5 & $\mathrm{R} \$ 144,00$ & \\
\hline LO & 3 & $\mathrm{R} \$ 111,59$ & \\
\hline Renovação LC & 2 & $R \$ 113,53$ & \\
\hline 2a via de LC & 1 & $\mathrm{R} \$ 17,77$ & \\
\hline 2ª via de LO & 4 & $R \$ 55,46$ & $\mathrm{R} \$ 101,43$ \\
\hline
\end{tabular}

Fonte: elaboração própria. 
O custo gerencial (indireto de pessoal) foi calculado considerando que o gerente direto da área ocupa aproximadamente $10 \%$ de seu tempo para fins de gerenciamento das atividades operacionais do departamento responsável pelo processamento das atividades de habilitação do TRIC. Assim, esse percentual foi aplicado ao salário anual do gerente, o que resultou em $\mathrm{R} \$ 14.814,06$. Tal montante foi rateado pelo tempo despendido por cada atividade do departamento. 0 resultado desses cálculos está resumido na Tabela 4, cujos valores referentes aos percentuais de tempo foram arredondados pelo software Excel.

Tabela 4 - Custo gerencial (indireto de pessoal) por atividade

\begin{tabular}{|c|c|c|c|c|}
\hline & $A$ & B & C & $\mathrm{D}$ \\
\hline Atividade & $\%$ Tempo & $\begin{array}{l}\text { Rateio do } \\
\text { salário } \\
\text { (“A” x salário } \\
\text { anual) }\end{array}$ & $\begin{array}{l}\text { Solicitações } \\
\text { processadas } \\
\text { em } 2016\end{array}$ & $\begin{array}{c}\text { Rateio por } \\
\text { solicitação } \\
\text { (B/C) }\end{array}$ \\
\hline $\begin{array}{l}L O, L C \text {, } \\
\text { renovação LC e } \\
\text { 2a via de LC e LO }\end{array}$ & $17,2 \%$ & $\mathrm{R} \$ 2.543,04$ & 524 & $R \$ 4,85$ \\
\hline Modelo "A" & $3,3 \%$ & $\mathrm{R} \$ 496,02$ & 301 & $\mathrm{R} \$ 1,65$ \\
\hline $\begin{array}{l}\text { Modificação de } \\
\text { frota }\end{array}$ & $75,8 \%$ & $\mathrm{R} \$ 11.225,98$ & 7.448 & $\mathrm{R} \$ 1,51$ \\
\hline $\begin{array}{l}\text { Viagem } \\
\text { ocasional }\end{array}$ & $3,7 \%$ & $\mathrm{R} \$ 549,02$ & 187 & $\mathrm{R} \$ 2,94$ \\
\hline Soma & $100 \%$ & $\mathrm{R} \$ 14.814,06$ & 8.460 & \\
\hline
\end{tabular}

Fonte: elaboração própria.

Para calcular os custos com instalação foram considerados os gastos com: aluguel, imposto (IPTU) e seguro do imóvel; energia elétrica; consumo de água; e gastos com vigilância, manutenção e limpeza da ANTT. Para o ano de 2016, a totalidade desses valores foi de $\mathrm{R} \$ 40.568 .358,10$. O rateio desse montante se deu pela área destinada exclusivamente para realização das atividades vinculadas ao $\operatorname{TRIC}\left(46,36 \mathrm{~m}^{2}\right)$, que corresponde a $0,12 \%$ da área total da sede $\left(38.876,91 \mathrm{~m}^{2}\right)$. Como resultado, os custos com instalação foram de $\mathrm{R} \$ 48.679,64$ para o ano de 2016. Esse montante foi rateado pelo percentual de tempo despendido em cada atividade da coordenação envolvida, conforme detalhado na Tabela 5. 
Tabela 5 - Custo com instalação rateado por atividade

\begin{tabular}{|c|c|c|c|c|}
\hline & $A$ & B & C & $\mathrm{D}$ \\
\hline Atividade & \% Tempo & $\begin{array}{l}\text { Rateio da } \\
\text { instalação } \\
\text { anual } \\
\text { (“A” x } \\
\text { Instalação) }\end{array}$ & $\begin{array}{c}\text { № } \\
\text { solicitações } \\
\text { processadas } \\
\text { em } 2016\end{array}$ & $\begin{array}{l}\text { Rateio por } \\
\text { solicitação } \\
\text { (B/C) }\end{array}$ \\
\hline $\begin{array}{l}\mathrm{LO}, \mathrm{LC} \text {, } \\
\text { renovação } \mathrm{LC} \text { e } \\
\text { 2a via de } \mathrm{LC} \text { e } \mathrm{LO}\end{array}$ & $17,2 \%$ & $\mathrm{R} \$ 8.356,55$ & 524 & $\mathrm{R} \$ 15,95$ \\
\hline Modelo "A" & $3,3 \%$ & $\mathrm{R} \$ 1.629,93$ & 301 & $\mathrm{R} \$ 5,42$ \\
\hline $\begin{array}{l}\text { Modificação de } \\
\text { frota }\end{array}$ & $75,8 \%$ & $\mathrm{R} \$ 36.889,06$ & 7.448 & $\mathrm{R} \$ 4,95$ \\
\hline $\begin{array}{l}\text { Viagem } \\
\text { ocasional }\end{array}$ & $3,7 \%$ & $\mathrm{R} \$ 1.804,10$ & 187 & $\mathrm{R} \$ 9,65$ \\
\hline Soma & $100 \%$ & $\mathrm{R} \$ 48.679,64$ & 8.460 & - \\
\hline
\end{tabular}

Etapa 4: identificação dos custos potenciais

Uma vez identificados os custos efetivos, esta quarta etapa analisou os gastos potenciais. Esses podem ser entendidos como custos de oportunidade, uma vez que não decorrem da efetiva execução das atividades principais do TRIC, tais como os gastos com processamento e postagem das multas ou com eventuais cobranças judiciais.

Para o ano de 2016, o desembolso com processamento de multas foi de $\mathrm{R} \$$ $543.532,56$. Excluiu-se do rateio os emolumentos relativos à solicitação de relatório de frota (Modelo A) que, como o próprio nome sugere, não diz respeito à licença ou autorização para operar no TRIC. Como houve a exclusão da atividade de emissão do Modelo $A$, foi necessário recalcular a proporção do tempo despendido nos processamentos das demais atividades. Por meio dessas proporções, foram rateados os $\mathrm{R} \$ 543.532,56$, conforme apresentado resumidamente na Tabela 6. 
Tabela 6 - Custo por processamento de multas por atividade

\begin{tabular}{lcccc} 
& A & B & C & D \\
\cline { 2 - 5 } & \% Tempo & $\begin{array}{l}\text { Rateio dos } \\
\text { custos com } \\
\text { proces. de } \\
\text { multas (Ax } \\
\text { Instalação) }\end{array}$ & $\begin{array}{c}\text { Solicitações } \\
\text { processadas } \\
\text { em 2016 }\end{array}$ & $\begin{array}{c}\text { Rateio por } \\
\text { solicitação } \\
\text { (B/C) }\end{array}$ \\
\hline $\begin{array}{l}\text { LO, LC, renovação } \\
\text { LC e 2a via de LC } \\
\text { e LO }\end{array}$ & $17,8 \%$ & $\mathrm{R} \$ 96.537,43$ & 524 & $\mathrm{R} \$ 184,23$ \\
\hline $\begin{array}{l}\text { Modificação de } \\
\text { frota }\end{array}$ & $78,4 \%$ & $\mathrm{R} \$ 426.153,61$ & 7.448 & $\mathrm{R} \$ 57,22$ \\
\hline $\begin{array}{l}\text { Viagem ocasional } \\
\text { Soma }\end{array}$ & $3,8 \%$ & $\mathrm{R} \$ 20.841,51$ & 187 & $\mathrm{R} \$ 111,45$ \\
\hline
\end{tabular}

Fonte: elaboração própria.

Em 2016, a ANTT gastou R\$78.209,29 com postagens e notificações de multas. Utilizando o mesmo critério de rateio realizado no cálculo de processamento das multas, tem-se a Tabela 7.

\section{Tabela 7 - Custo com postagem de multas}

\begin{tabular}{|c|c|c|c|c|}
\hline & $A$ & B & C & D \\
\hline Atividade & \% Tempo & $\begin{array}{l}\text { Rateio dos } \\
\text { custos com } \\
\text { proces. de } \\
\text { multas (“A” x } \\
\text { Instalação) }\end{array}$ & $\begin{array}{c}\mathrm{n} \text { o } \\
\text { solicitações } \\
\text { processadas } \\
\text { em } 2016\end{array}$ & $\begin{array}{l}\text { Rateio por } \\
\text { solicitação } \\
\text { (B/C) }\end{array}$ \\
\hline $\begin{array}{l}\text { LO, LC, renovação } \\
\text { LC e } 2^{\text {a }} \text { via de } L C \\
\text { e LO }\end{array}$ & $17,8 \%$ & $\mathrm{R} \$ 13.890,84$ & 524 & $\mathrm{R} \$ 26,51$ \\
\hline $\begin{array}{l}\text { Modificação de } \\
\text { frota }\end{array}$ & $78,4 \%$ & $\mathrm{R} \$ 61.319,55$ & 7448 & $\mathrm{R} \$ 8,23$ \\
\hline Viagem ocasional & $3,8 \%$ & $\mathrm{R} \$ 2.998,90$ & 187 & $\mathrm{R} \$ 16,04$ \\
\hline Soma & $100 \%$ & $\mathrm{R} \$ 78.209,29$ & 8.159 & - \\
\hline
\end{tabular}

Para cálculo com cobranças judiciais, utilizaram-se como referência os valores apresentados pela nota técnica do Instituto de Pesquisa Econômica Aplicada (Ipea) (CUNHA; KLIN; PESSOA, 2011), a qual apresenta custo médio de $\mathrm{R} \$ 5.606,67$ 
por cobrança. No ano de 2016, a ANTT contabilizou cinco cobranças judiciais processadas, o que totalizaria aproximadamente $\mathrm{R} \$ 28.033,35$. A atividade de modificação de frota foi eliminada do rateio, tendo em vista que não há cobranças judiciais diretamente relacionadas com essa operação. Os resultados estão apresentados na Tabela 8.

Tabela 8 - Custo com cobranças judiciais rateado por atividade

\begin{tabular}{lcccc} 
& A & B & C & D \\
\hline & \% Tempo & $\begin{array}{l}\text { Rateio dos } \\
\text { custos com } \\
\text { cobranças } \\
\text { judiciais (“A" } \\
\text { x Instalação) }\end{array}$ & $\begin{array}{c}\text { no } \\
\text { solicitações } \\
\text { processadas } \\
\text { em 2016 }\end{array}$ & $\begin{array}{c}\text { Rateio por } \\
\text { solicitação } \\
\text { ("B" / “C”) }\end{array}$ \\
\hline $\begin{array}{l}\text { LO, LC, renovação LC } \\
\text { e 2a via de LC e LO }\end{array}$ & $82,2 \%$ & $\mathrm{R} \$ 23.055,82$ & 524 & $\mathrm{R} \$ 44,00$ \\
\hline Viagem ocasional & $17,8 \%$ & $\mathrm{R} \$ 4.977,53$ & 187 & $\mathrm{R} \$ 26,62$ \\
\hline Soma & $100 \%$ & $\mathrm{R} \$ 28.033,35$ & 711 & - \\
\hline Fonte: elaboração própria. & & & & \\
\hline
\end{tabular}

\section{Etapa 5: identificação do custo total da atividade}

Essa quinta etapa do MIVE consolidou os cálculos dos custos efetivos e potenciais, e o resultado de seu somatório foi o custo total das atividades. O resultado desse montante está resumidamente apresentado na Tabela 9.

Tabela 9 - Resumo do rateio dos custos identificados por atividade

\begin{tabular}{|c|c|c|c|c|c|c|c|}
\hline \multirow[b]{2}{*}{ Atividade } & \multicolumn{3}{|c|}{ Custos efetivos } & \multicolumn{3}{|c|}{ Custos potenciais } & \multirow[b]{2}{*}{ Total } \\
\hline & $\begin{array}{c}\text { Custo } \\
\text { direto de } \\
\text { pessoal }\end{array}$ & $\begin{array}{c}\text { Custo } \\
\text { gerencial }\end{array}$ & $\begin{array}{l}\text { Custo com } \\
\text { instalação }\end{array}$ & $\begin{array}{c}\text { Custo com } \\
\text { processamento } \\
\text { de multas }\end{array}$ & $\begin{array}{c}\text { Custo } \\
\text { com } \\
\text { postagem }\end{array}$ & $\begin{array}{l}\text { Custo com } \\
\text { cobranças } \\
\text { judiciais }\end{array}$ & \\
\hline $\begin{array}{l}\text { LC, LO, } \\
\text { renovação } \\
\text { LC/LO, 2a } \\
\text { via LC/LO }\end{array}$ & $\$ 101,43$ & $\mathrm{R} \$ 4,85$ & $R \$ 15,95$ & $\mathrm{R} \$ 184,23$ & $R \$ 26,51$ & $\mathrm{R} \$ 44,00$ & $\mathrm{R} \$ 376,97$ \\
\hline Modelo A & $\mathrm{R} \$ 30,48$ & $\mathrm{R} \$ 1,65$ & $\mathrm{R} \$ 5,42$ & - & - & - & $R \$ 37,55$ \\
\hline MF & $\mathrm{R} \$ 82,23$ & $\mathrm{R} \$ 1,51$ & $\mathrm{R} \$ 4,95$ & $\mathrm{R} \$ 57,22$ & $\mathrm{R} \$ 8,23$ & - & $\mathrm{R} \$ 154,14$ \\
\hline Vo & $\mathrm{R} \$ 46,43$ & $\mathrm{R} \$ 2,94$ & $\mathrm{R} \$ 9,65$ & $\mathrm{R} \$ 111,45$ & $\mathrm{R} \$ 16,04$ & $\mathrm{R} \$ 26,62$ & $\mathrm{R} \$ 213,13$ \\
\hline
\end{tabular}

Fonte: elaboração própria. 
É válido relembrar que a primeira linha da Tabela 9 dispõe um resultado agregado para os cinco documentos relativos às licenças complementares e licenças originárias, sendo eles: LC, LO, renovação LC/LO, 2a via LC/LO. A agregação foi realizada devido à similaridade das atividades realizadas e para fins de simplificação de rateio.

Para desagregar esses valores, tomou-se como base o tempo de processamento de cada atividade anteriormente agrupada. Foi considerada tarefa de referência a execução dos formulários de LC e LO, cujo tempo médio ponderado resultou em aproximadamente $3 \mathrm{~h} 16 \mathrm{~min}$. A partir daí, definiu-se que os $\mathrm{R} \$ 376,97$ de custo total são referentes às $3 \mathrm{~h} 16 \mathrm{~min}$ dessas atividades, e que as atividades de renovação de licenças e emissão de 2 a via, demandantes de menos horas de serviço, deveriam ser mais baratas. Por essa razão, tratou-se como $2 \mathrm{~h} 30 \mathrm{~min}$ o tempo de execução da renovação de documento; e 1h05min, o tempo médio ponderado de execução de 2a via de LC e LO, sendo possível, a partir daí, calcular os emolumentos de cada uma dessas atividades (Tabela 10).

\section{Tabela 10 - Fatores de ponderação dos valores para fins de desagregação de atividades}

\begin{tabular}{lccc}
\hline & A & B & C \\
\cline { 2 - 4 } Tempo & Tempo de ref. & $\begin{array}{c}\text { \% do Temp. } \\
\text { ref. }\end{array}$ & Custo total \\
\hline $\begin{array}{l}\text { Tempo médio de execução LC } \\
\text { e LO }\end{array}$ & $03: 16: 15$ & $100,00 \%$ & $\mathrm{R} \$ 376,97$ \\
\hline $\begin{array}{l}\text { Tempo médio de execução da } \\
\text { renovação }\end{array}$ & $02: 32: 30$ & $77,71 \%$ & $\mathrm{R} \$ 292,93$ \\
\hline $\begin{array}{l}\text { Tempo médio de execução da } \\
\text { 2a via LC e LO }\end{array}$ & $01: 05: 00$ & $33,12 \%$ & $\mathrm{R} \$ 124,86$ \\
\hline \begin{tabular}{l} 
Fonte: elaboração própria. \\
\hline
\end{tabular} & & & \\
\hline
\end{tabular}

Considerando os problemas identificados no mapeamento do processo, para redução de custos dos transportadores e de processamento da ANTT, propõe-se a criação de uma Habilitação TRIC, cujo cálculo de emolumentos seria realizado de forma análoga à emissão de uma LO ou de uma LC. Do mesmo modo, propõe-se a criação da autorização TRIC própria, a qual teria valor semelhante à VO. Ademais, destaca-se o pressuposto de que o cálculo considera a cobrança de valores únicos, independentemente da quantidade de veículos existentes em cada requerimento, a fim de evitar erros nos pagamentos. Dessa forma, a partir dos resultados encontrados até então, foi proposto que a nova tabela de emolumentos tivesse oito tipos de solicitação, cujos valores estão arredondados na Tabela 12. 
Tabela 11 - Proposta da tabela de emolumentos, considerando os custos efetivos e potenciais

\begin{tabular}{|c|c|c|c|}
\hline Solicitação & $\begin{array}{l}\text { Rateio } \\
\text { calculado }\end{array}$ & $\begin{array}{l}\text { Proposta de } \\
\text { emolumento }\end{array}$ & Valor atual \\
\hline $\begin{array}{l}\text { Habilitação para prestação } \\
\text { de serviço de TRIC }\end{array}$ & $\mathrm{R} \$ 376,97$ & $\mathrm{R} \$ 370,00$ & Não há \\
\hline $\begin{array}{l}\text { Autorização de viagem } \\
\text { ocasional (empresa } \\
\text { brasileira) }\end{array}$ & $\mathrm{R} \$ 213,13$ & $\mathrm{R} \$ 210,00$ & $\begin{array}{l}\mathrm{R} \$ 10,00 \text { fixo }+ \\
\mathrm{R} \$ 5,00 \text { por } \\
\text { veículo }\end{array}$ \\
\hline Autorização de TRIC própria & $\mathrm{R} \$ 213,13$ & $\mathrm{R} \$ 210,00$ & Não há \\
\hline Modificação de frota & $\mathrm{R} \$ 154,14$ & $\mathrm{R} \$ 150,00$ & $\begin{array}{l}\mathrm{R} \$ 10,00 \text { fixo }+ \\
\mathrm{R} \$ 5,00 \text { por } \\
\text { veículo }\end{array}$ \\
\hline $\begin{array}{l}\text { Licença complementar } \\
\text { (empresa estrangeira) }\end{array}$ & $\mathrm{R} \$ 376,97$ & $\mathrm{R} \$ 370,00$ & $\mathrm{R} \$ 180,00$ \\
\hline $\begin{array}{l}\text { Modelo A (relatório de } \\
\text { frota) }\end{array}$ & $\mathrm{R} \$ 37,55$ & $\mathrm{R} \$ 40,00$ & $\mathrm{R} \$ 50,00$ \\
\hline Renovação de licenças & $R \$ 292,93$ & $\mathrm{R} \$ 290,00$ & Não há \\
\hline $\begin{array}{l}\text { 2a via de licença } \\
\text { complementar (emp. } \\
\text { estrangeira) }\end{array}$ & $\mathrm{R} \$ 124,86$ & $\mathrm{R} \$ 130,00$ & $\mathrm{R} \$ 180,00$ \\
\hline
\end{tabular}

\section{Etapa 6: análise comparativa do custo total identificado}

Nessa última etapa do MIVE, propõe-se verificar os valores dos emolumentos com a realidade do setor. Para comparar os valores obtidos, foram solicitadas à Associação Brasileira de Transportadores Internacionais (ABTI) informações sobre o valor de cobranças pelas licenças complementares dos demais países signatários de acordos de transporte em meados de 2017. Em resposta, os governos da Bolívia, Chile e Uruguai não cobram emolumentos pela emissão de licenças complementares. Por outro lado, as autoridades da Argentina cobram aproximadamente $\mathrm{R} \$ 360,00$, e do Paraguai cobram aproximadamente $\mathrm{R} \$ 430,00$ (em meados de 2017). Isso indicou que a proposta de cobrar $\mathrm{R} \$ 370,00$ por uma licença complementar está coerente como boas práticas de reciprocidade. 
Ademais, não haveria cobrança por licença originária, e sim apenas para a habilitação TRIC. Também se destaca que os valores calculados para os emolumentos não exigem cobrança por veículo, e sim por solicitação. Nesse novo cenário, não houve grande discrepância dos valores praticados em 2017 com aqueles apresentados na proposta. Acerca dessa afirmação, ressalta-se que os valores considerados como vigentes não são reajustados desde 2003, bem como que, segundo a calculadora disponível no sítio eletrônico do Banco Central do Brasil, entre 2003 e 2017 a inflação medida por meio do Índice Nacional de Preços ao Consumidor Amplo (IPCA) superou 120\%. Dessa forma, conclui-se que os valores propostos para os emolumentos são aderentes àqueles com os quais a sociedade arca atualmente, e seria capaz de proporcionar simplificação administrativa nos processos internos e externos à ANTT.

\section{Conclusões}

Este artigo desenvolveu um método para facilitar o cálculo de emolumentos cobrados no serviço público brasileiro. A técnica, intitulada de MIVE (método de identificação de valores de emolumentos), foi elaborada por meio da adaptação de conceitos do standard cost model, amostragem do trabalho e custeio baseado em atividades. Em resumo, o método é composto por seis etapas: (i) mapeamento das atividades; (ii) identificação do tempo despendido por atividade; (iii) identificação dos gastos efetivos da atividade; (iv) identificação dos gastos potenciais envolvidos na atividade; (v) identificação do custo total da atividade (valor do emolumento), e; (vi) análise comparativa do custo total identificado.

Ao final, o MIVE se mostrou eficaz para legitimar o cálculo dos valores de emolumentos cobrados da sociedade. Por meio dessa técnica, o gestor público também passou a ter uma referência metodológica capaz de identificar eventuais desperdícios existentes durante a realização de atividades que, em alguns casos, além de custeadas pelos usuários dos serviços, também recebem contrapartida financeira do Estado.

Para comprovar sua aderência ao objetivo proposto, o método desenvolvido foi aplicado às atividades da ANTT que envolvem a habilitação do transporte rodoviário internacional de cargas (TRIC), as quais são consideradas de grande complexidade e de importância estratégica em todos os blocos econômicos em que há acordos de transporte terrestre. Como resultado, a aplicação dessa técnica não apenas cumpriu com o objetivo principal de propor a nova tabela de emolumentos baseada nos custos reais do processamento das atividades, mas também proporcionou a oportunidade de aprimorar os processos que se apresentavam menos eficientes. 
A conclusão geral a que se chegou foi que o MIVE possui grande potencial para ser utilizado na administração pública, tanto para calcular os valores de emolumentos baseados nos custos de atividades altamente complexas, quanto para desenvolver a melhoria nos processos avaliados e a sua simplificação administrativa. A técnica também se mostrou adaptável à realidade de cada instituição, o que a torna flexível conforme a necessidade do gestor. Esse método foi aprovado pela equipe técnica da ANTT responsável pelo TRIC e auxiliou na fundamentação de uma nova proposta regulatória.

\section{Referências bibliográficas}

AgÊnCIA Nacional de TRANSPORTES TERRESTREs (ANTT). Resolução ANTT $n$ o 363, de 26 de novembro de 2003. Dispõe sobre os procedimentos relativos à expedição de Licença Originária e Autorização de Caráter Ocasional, para empresas nacionais de transporte rodoviário de cargas autorizadas a operar no transporte rodoviário internacional entre os países da América do Sul e de Licença Complementar e de Trânsito, em caso de empresas estrangeiras, e dá outras providências. Publicado no DOU em 27 de novembro de 2003.

AgÊncia nacional de Transportes Terrestres (ANTT). Resolução ANTT no 1.474, de 31 de maio de 2006. Dispõe sobre os procedimentos relativos à expedição de Licença Originária, de Autorização de Caráter Ocasional, para empresas nacionais de transporte rodoviário de cargas autorizadas a operar no transporte rodoviário internacional entre os países da América do Sul, e de Licença Complementar, em caso de empresas estrangeiras, e dá outras providências. Publicado no DOU em 5 de junho de 2006.

Atonso, M. Custos no serviço público. Revista do Serviço Público, v. 50, n. 1, p. 3763, 1999.

Amaral, N. A. D. L.; Bolfe, C.; Borgert, A.; Vicente, E. F. R. O sistema de custos do governo federal e as responsabilidades dos contadores das IFES. Revista de Contabilidade do Mestrado em Ciências Contábeis da UERJ, v.19, n. 2, p. 23-39, 2014.

Avenali, A.; Boitani, A.; Catalano, G.; D’Alfonso, T., Matteucci, G. Assessing standard costs in local public bus transport: a hybrid cost model. Transport Policy, v.52, n. 1, p. 164-174 2016.

BARNES, R. M. Estudo de movimentos e de tempos. 6. ed. São Paulo: Edgard Blücher, 1982.

BARNES, R. M. Estudo de movimentos e de tempos: projeto e medida do trabalho. São Paulo: Editora Edgard Blu cher, 1977.

Borinelli, B.; AmÂncio-Vieira, S. F.; Negreiros, L. F. D.; Pereira, R. S.; Pereira, R. R. G. Relação entre custos, desempenho e variáveis educacionais do ensino fundamental: um estudo de caso em Ibiporã-PR. Revista do Serviço Público, v. 65, n. 3, p. 335-354, 2014. 
BRASIL. Constituição da República Federativa do Brasil. Promulgada em 5 de outubro de 1988. Contém as emendas constitucionais posteriores. Brasília, DF: Senado, 1988.

BRASIL. Lei no 5.172, de 25 de outubro de 1966. Dispõe sobre o Sistema Tributário Nacional e institui normas gerais de direito tributário aplicáveis à União, Estados e Municípios. Diário Oficial da União, Atos do Poder Legislativo, Brasília, DF, 27 out. 1966.

BRASIL. Lei no 10.233 , de 5 de junho de 2001. Dispõe sobre a reestruturação dos transportes aquaviário e terrestre, cria o Conselho Nacional de Integração de Políticas de Transporte, a Agência Nacional de Transportes Terrestres, a Agência Nacional de Transportes Aquaviários e o Departamento Nacional de Infra-Estrutura de Transportes, e dá outras providências. Diário Oficial da União, Atos do Poder Legislativo, Brasília, DF, 06 jun. 2001.BRASIL. Supremo Tribunal Federal. Ação declaratória de constitucionalidade no 5. Distrito Federal. Relator: Ministro Nelson Jobim. Pesquisa de Jurisprudência, Acórdãos, Liminar julgada em 17 de novembro de 1999. <http://www.stf.jus.br/portal /jurisprudencia/pesquisarJurisprudencia. asp>. Acesso em: 08 dez. 2017.

BRASIL. Supremo Tribunal Federal. Ação direta de inconstitucionalidade no 1.378. Espírito Santo. Relator: Ministro Celso de Mello. Pesquisa de Jurisprudência, Acórdãos, liminar julgada em 30 de novembro de 1995. <http://www.stf.jus.br/ portal /jurisprudencia/pesquisarJurisprudencia.asp>. Acesso em: 08 dez. 2017.

Catelli, A.; Parisı, C.; SAntos, E. S.; De Almeida, L. B. Um sistema para a gestão econômica de organizações governamentais empreendedoras. Revista do Serviço Público, v. 52, n. 3, p. 82-99, 2014.

Chiavenato, I. Princípios de administração. Rio de Janeiro: Campus, 2006.

CUNHA, A. S.; KLIN, I. V.; PESSOA, O. A. G. Custo e tempo de processo de execução fiscal promovido pela Procuradoria Geral da Fazenda Nacional. Nota técnica do Instituto de Pesquisa Econômica e Aplicada. 2011. Disponível em: <http://www.ipea.gov. br/agencia/images/stories/PDFs/nota_tecnica/111230_notatecnicadiest1.pdf >. Acesso em: 18 fev. 2017.

Den-Butter, F.A.G.; De-GraAF, M.; NIJSEN, A. The transaction costs perspective on costs and benefits of government regulation: extending the standard cost model. Tinbergen Institute Discussion Paper, v. 13, n. 3, p 1-32, 2009.

hamann, E. V.; Souza-Bezerra, P. C.; Coutinho, J. F.; Sousa, N. B. Custos para o julgamento de um processo no Tribunal de Justiça do Distrito Federal-TJDF. In: Congresso Brasileiro de Custos-ABC. Anais, 2014.

Librelotto, L. I.; Mutti, C. D. N.; OliveirA, P. D.; Jungles, A. E. Análise do emprego dos tempos de mão de obra utilizando a técnica de amostragem do trabalho. In: III Encontro Nacional de Tecnologia do Ambiente Construído. Anais, 2000.

luque, C. A.; Cruz, H. N.; Amaral, C. M.; Bender, S.; Santos, P. M. D. O processo orçamentário e a apuração de custos de produtos e serviços no setor público do Brasil. Revista do Serviço Público, v. 59, n. 3, p. 309-331, 2008. 
MAHer, M. Contabilidade de custo. São Paulo: Atlas, 2001.

MARTINS, E. Contabilidade de Custos: o uso da contabilidade de custos como instrumento gerencial de planejamento e controle. São Paulo: Atlas, 2003.

Neyt, M. J.; Albrecht, J. A.; Clarysse, B.; Cocquyt, V. F. Cost-effectiveness of Herceptin: a standard cost model for breast-cancer treatment in a Belgian university hospital. International journal of technology assessment in health care, v. 21, n. 1, p. 132-137, 2005.

NIJSEN, A.F.M.; VellingA. N. M. MISTRAL: a Model to Measure the Administrative Burden of Businesses. EIM, Business \& Policy Research: Zoetermeer , Vol. 0110, 2002.

NoRdstrom, Joseph A. A amostragem de trabalho. Revista de Administração de Empresas, v. 1, n. 3, p. 29-42, 1961.

ORGANISATION FOR ECONOMIC CO-OPERATION AND DEVELOPMENT (OECD). International Standard Cost Model Manual: measuring and reducing administrative burdens for businesses. Directorate for Public Governance and Territorial Development, 2004. Disponível em: www.oecd.org/gov/regulatory-policy/34227698.pdf. Acesso em 18 dez. 2017.

OSEIFUAH, E. K. Activity based costing $(A B C)$ in the public sector: benefits and challenges. Problems and Perspectives in Management, v. 12, n. 4, p. 581-588, 2014.

Pinho, A. F.; Leal, F.; Montevechi, J. A. B.; AlmeidA, D. A. Combinação entre as técnicas de fluxograma e mapa de processo no mapeamento de um processo produtivo. In: Encontro NACIONAL DE ENGenhaRIA DE ProduçÃo (Enegep), 27. Anais, 2007.

RiBeIRo, H. A. S. Modelo de simulação para análise de processos de aeroporto de médio porte. 2015. 121f. Dissertação (Mestrado em Engenharia de Produção) Universidade Federal de São Carlos, São Carlos, SP, 2015.

SABBAG, E. Manual de direito tributário. São Paulo: Saraiva, 2010. 427 p.

StePHEN, F. H. Teoria Econômica do Direito. São Paulo: Makron Books, 1993

SILVA, A. S.; DAVIS, M. D.; VIVEIROS, A R. Contabilidade de Custos na Administração Pública: o Estabelecimento dos Gatos de Posse Estratégica na Marinha do Brasil. Revista do Serviço Público, v. 59, n. 4, p. 421-440, 2014.

VARIAN, H. R. Microeconomia: princípios básicos. Rio de Janeiro: Elsevier, 2003.

Vazakidis, A; KaragianNis, I; TSIalta, A. Activity-Based Costing in the Public Sectorbased costing in the public sector and cost of service organizations. Journal of Social Sciences, v. 6, n. 3, p. 376-382, 2010. 


\section{Gizelle Coelho Netto}

Agência Nacional de Transportes Terrestres (ANTT). Mestre em Transportes pela Universidade de Brasília. Especialista em Regulação da Agência Nacional de Transportes Terrestres.

\section{Nathane Eva Santos Peixoto}

Instituto Federal de Brasília (IFB). Mestre em Transportes pela Universidade de Brasília. Doutoranda em Administração na Universidade de Brasília. Professor de Gestão do Instituto Federal de Brasília.

\section{Carlos Henrique Rocha}

Universidade de Brasília (UnB). PhD em Economia pela Universidade de Liverpool. Mestre em Teoria Econômica pela Universidade de Manchester. Professor na Universidade de Brasília. 